Smoking habits of patients with primary spontaneous pneumothorax (group 1), other patients (group 2), and normal people (group 3). Results are numbers (percentages) of patients

\begin{tabular}{|c|c|c|c|c|c|c|c|c|c|c|}
\hline & \multirow{2}{*}{$\begin{array}{c}\text { No of } \\
\text { subjects }\end{array}$} & \multirow{2}{*}{$\begin{array}{c}\text { Mean }( \pm \mathrm{SD}) \\
\text { age (years) } \\
\text { (range) }\end{array}$} & \multirow{2}{*}{ Non-smokers } & \multirow{2}{*}{ Ex-smokers } & \multirow{2}{*}{$\begin{array}{l}\text { Pipe and } \\
\text { cigar } \\
\text { smokers }\end{array}$} & \multicolumn{4}{|c|}{ Cigarettes per day } & \multirow{2}{*}{$\begin{array}{c}\text { Mean cigarette } \\
\text { consumption } \\
(\text { No/day)* }\end{array}$} \\
\hline & & & & & & $1-4$ & $5-14$ & $15-24$ & $>25$ & \\
\hline Group 1 & 44 & $\begin{array}{l}26 \pm 6 \\
(16-45)\end{array}$ & $2(5)$ & $1(2)$ & $0(0)$ & $1(2)$ & $11(25)$ & $21(48)$ & $8(18)$ & $17 \pm 8$ \\
\hline Group 2 & 44 & $27 \pm 6$ & $14(32)$ & $1(2)$ & $2(5)$ & $3(7)$ & $8(18)$ & $12(27)$ & $4(9)$ & $10 \pm 10$ \\
\hline Group 3 & 489 & $\begin{array}{l}(18-39) \\
29 \pm 6 \\
(18-39)\end{array}$ & $105(22)$ & $84(17)$ & $20(4)$ & $17(3)$ & $100(20)$ & $99(20)$ & $64(13)$ & $10 \pm 11$ \\
\hline
\end{tabular}

*Based on assumption that mean cigarette consumption was 0 in non-smokers, ex-smokers, and pipe and cigar smokers and $29 \frac{1}{2}$ in people smoking $>25$ cigarettes a day.

with those of the normal population. Our control group (2) showed a pattern of cigarette consumption similar to that of the normal population (group 3) except for the ex-smokers. Probably most exsmoker patients called themselves non-smokers because no special question was posed on their former smoking habits.

Though in our series patients with apparent lung disease were not included the smoking habits of our patients agreed with those of Zivy's patients : only two of their patients had never smoked, two were ex-smokers, 35 smoked more than five cigarettes a day, and 27 admitted smoking more than 15 cigarettes a day.

Our data show that patients with primary spontaneous pneumothorax smoke considerably more than normal people. Thus heavy smoking is probably important in the aetiology of primary spontaneous pneumothorax although it is not the only factor. The relation between heavy smoking and primary spontaneous pneumothorax does not exclude an inherited predisposition to this condition. The preponderance of men $(85-95 \%)$ with primary spontaneous pneumothorax ${ }^{2}$ cannot merely be explained by thei heavier smoking habits; in Holland $60 \%$ of the men and $40 \%$ of the women are regular smokers. ${ }^{.}$Differences in mechanical forces in the lung between men and women may be important. ${ }^{5}$ As heavy smokers form a high risk group for spontaneous pneumothorax, patients with this condition who smoke should be strongly advised to stop.

We thank W H Doesburg and V Lauret for their statistical advice, C R Layton for his critical remarks, and $R$ van der Lende, head of the Research Unit for Epidemiology of CNSLD of the Organisation for Health Research TNO, the Netherlands, for help in selecting group 3.

1 Killen, D A, and Gobbel, W G, Spontaneous Pneumothorax. Boston, Little, Brown and Company, 1968.

2 British Medical fournal, 1968, 1, 720

${ }^{3}$ Zivy, P, Revue de Tuberculose et de Pneumologie, 1970, 34, 125.

4 Haas, J H de, Hartbulletin, 1973, 4, 77.

5 British Medical fournal, 1971, 4, 573.

Department of Pulmonary Diseases, St Radboud Hospital, University of Nijmegen, Netherlands

C A F JANSVELD, MD, chest physician (present address: Catharina Hospital, Eindhoven, Netherlands)

J H DIJKMAN, MD, associate professor of medicine

\section{High density polyethylene plate for fracture fixation in the elderly}

Screws are often difficult to fix firmly in osteoporotic bone. A plate applied to the bone shaft may distract from the cortex as the screws loosen and the fracture will be displaced. Any operation for a broken leg in an elderly patient must allow for immediate mobilisation ${ }^{1}$ and therefore an internal fixation is required which remains firmly in position when the limb is used.

\section{Material and method}

The plate is of high density polyethylene $3 \mathrm{~mm}$ thick, $1.8 \mathrm{~cm}$ wide, and varying in length from 2 to $16 \mathrm{~cm}$. It is curved in its transverse axis to lie

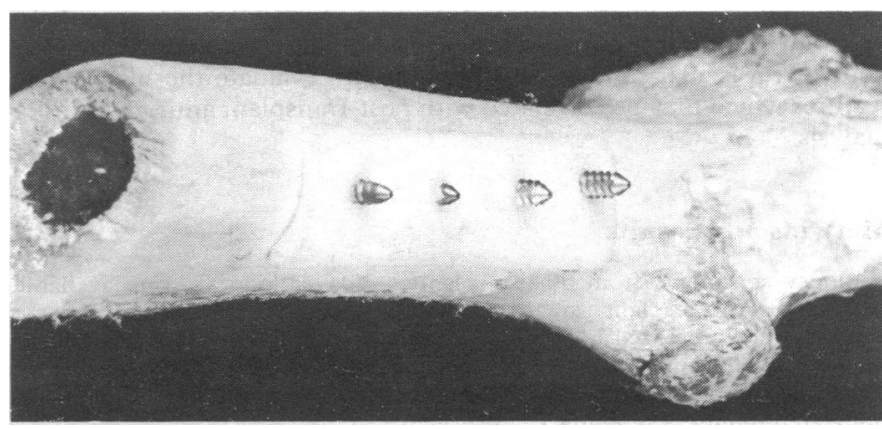

Cadaver specimen showing plate conforming to shape of bone when screws are tightened.

against the shaft of a long bone and has a radio-opaque marker in each of its four corners. The plates are individually packed and sterilised by $\gamma$ irradiation.

The bone is drilled in the normal manner and the drill passed through the polyethylene plate, which has been applied to the far cortex and held against the shaft of the bone with bone holders to prevent it from being pushed away from the cortex as drilling proceeds. A screw is then screwed through the metal plate and the bone to engage in the polyethylene plate, the thickness of which allows the thread of the screw to be firmly engaged while at the same time it will bend to adapt to the contour of the bone (see fig). As the screws are tightened the plate tends to flatten in its transverse axis, thus giving rise to some compression between the plate and bone cortex.

Laboratory tests showed that a buttress-thread screw pulled out of the polyethylene plate when a distraction force of $111 \mathrm{lb}(50.5 \mathrm{~kg})$ was applied. In the case of a self-tapping screw a force of $104 \mathrm{lb}(47 \cdot 2 \mathrm{~kg})$ was required.

\section{Comment}

High density polyethylene plates are of particular value when the bone is soft or a fracture is comminuted. They have been used most often in combination with a metal plate in the management of elderly patients with supracondylar or trochanteric fractures of the femur. Not uncommonly in these cases a metal plate distracts from the lateral aspect of the shaft when the patient starts to walk, ${ }^{2}$ and a number of patients in whom this occurred have had a second operation at which a high density polyethylene plate was applied to the medial cortex of the bone. This provided rigid fixation and enabled the patients to walk while the fracture healed, thus hastening their return home. I now use high density polyethylene plates at the first operation in patients with osteoporosis or when the screws for any reason fail to obtain a firm hold in the bone.

The plates are made by Zimmer (Orthopaedic) (GB) Limited and a provisional patent application (No 13367/75) has been filed. They were originally developed in the Orthopaedic Research Departments of the Royal East Sussex Hospital, Hastings, and the Redhill General Hospital, Surrey. I am grateful to $\mathrm{Mr}$ W $\mathrm{T}$ Bond for doing the distraction tests on the plates.

${ }^{1}$ Devas, M B, and Irvine, R E, fournal of Bone and foint Surgery, 1967, $49 \mathrm{~B}, 186$.

2 Gallannaugh, S C, British fournal of Accident Surgery, 1974, 5, 259. 